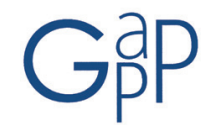

GESTIÓN Y ANÁLISIS DE POLÍTICAS PÚBLICAS, Nueva Época - N.º 15, enero-junio 2016 - ISSN: 1989-8991

DOI: http://dx.doi.org/10.24965/gapp.voi15.10310

Enrique Conejero Paz

Universidad Miguel Hernández

ecp@umh.es

Juan Carlos Redondo Lebrero

Universidad Rey Juan Carlos

juancarlosredondo@yahoo.es

\title{
La innovación social desde el ámbito público: Conceptos, experiencias y obstáculos ${ }^{1}$
}

\section{Resumen}

Este estudio se centra en la innovación social, aproximación conceptual emergente para conformar y explicar las relaciones entre el estado, la sociedad y el mercado. En este sentido, los gobiernos están comenzando a incluir en sus agendas programas de innovación social con distintos enfoques, aunque su implementación y evaluación aún denotan deficiencias debido a la existencia de determinadas barreras de carácter estructural. El trabajo se realiza desde un enfoque de gobernanza, residiendo su novedad, por un lado, el propio tratamiento de la innovación social, poco estudiada en España y, por otro, la integración en el análisis tres elementos; los enfoques de la innovación social, su aplicación en políticas públicas nacionales, y los obstáculos que inhiben la innovación social en el sector público.

\section{Palabras clave}

Innovación social, valor público, enfoques de la innovación social, Big Society, Innovation Union, barreras a la innovación social.

\section{Social innovation in the public sphere: Concepts, experiences and obstacles}

\section{Abstract}

This study focuses on social innovation, emerging conceptual approach to shape and explain the relationships between the state, society and the market. In this sense, governments are beginning to include in their agendas social innovation programs with different approaches, but its implementation and evaluation still denote deficiencies due to the existence of certain structural barriers. The work is done from a governance approach, its novelty residing on the one hand, the treatment of social innovation itself, little studied in Spain and on the other, integration into analysis three elements; approaches to social innovation, their application in national policies, and social obstacles that inhibit social innovation in the public sector.

\section{Keywords}

Social innovation, public value, approaches to social innovation, Big Society, Innovation Union, barriers to social innovation.

1 El texto que se presenta forma parte de una investigación más amplia impulsada por el Instituto Nacional de Administración Pública en colaboración con la Universidad Miguel Hernández de Elche bajo el título "La innovación social y la creación de valor público". 


\section{SUMARIO}

\section{Introducción.}

\section{Las concepciones de la innovación social.}

1.1. El enfoque económico-gerencial.

1.2. Los enfoques sociales (cultural y ecológico).

1.3. El enfoque de la ciencia política y de la administración.

1.4. Balance de los enfoques de innovación social.

2. Experiencias internacionales de innovación social en el ámbito público.

2.1. Big Society. Reino Unido.
2.1.1. Principios.
2.1.2. Actores.
2.1.3. Políticas y programas.
2.1.4. Impacto y resultados.

2.2. Social Innovation and Civic Participation. Estados Unidos.
2.2.1. Principios.
2.2.2. Actores.
2.2.3. Políticas y programas.
2.2.4. Impacto y resultados.

2.3. Innovation Union. Unión Europea.
2.3.1. Principios.
2.3.2. Actores.
2.3.3. Políticas y programas.
2.3.4. Impacto y resultados.

2.4. Balance de los programas gubernamentales de innovación social.

\section{Barreras a la innovación social.}

\section{Conclusiones.}

\section{Bibliografía.}

\section{INTRODUCCIÓN}

Desde hace una década la teoría y la praxis sobre la innovación social ha ido creciendo rápidamente. Al mismo tiempo, muchas necesidades, demandas y expectativas de los ciudadanos no se abordan eficazmente por parte de los poderes públicos, en un contexto de creciente desafección ciudadana y déficit de legitimad del sistema político democrático. Por tanto, los desafíos sociales exigen una nueva perspectiva en el análisis y la aplicación de la innovación. En este sentido, la innovación social puede ser vista como una nueva forma de suplir los fallos del Estado y del mercado en materias clave que preocupan a las sociedades como la pobreza, el envejecimiento de la población, los flujos migratorios o el cambio climático a través de fórmulas cooperativas y colaborativas con agentes y redes de actores.

Sin embargo, en la literatura actual no existe un acuerdo generalizado respecto a lo que significa la innovación social al configurarse ésta como un concepto de carácter multidimensional que ha sido tratado desde diferentes escuelas de pensamiento. Por ello, en primer lugar se realizará una revisión comparativa de las diferentes conceptualizaciones de la innovación social y de los distintos enfoques que han analizado la misma con el objeto de entender sus alcances y significados.

En relación con lo anterior, comienza a percibirse cierta institucionalización, aún incipiente, de la innovación social en las políticas de los gobiernos. Durante el último lustro se han puesto en marcha tres importantes iniciativas; la administración Obama en EEUU crea en 2009 la Office of Social Innovation and Civic Participation², ubicada

2 Para su impulso inicial fue dotada de 50 millones de dólares en el presupuesto de 2010, http://www.whitehouse.gov/administration/ eop/sicp. (Consulta: 12-05-2015). 
dentro del Consejo de Política Nacional de la Casablanca, enfocando sus líneas de actuación en la creación de nuevos líderes comunitarios, el desarrollo nuevas formas de parternariado público-privado y el fomento del servicio público como una manera de desarrollar el liderazgo de la comunidad; el gobierno de Cameron en el Reino Unido aprueba en 2010 el programa Big Society como un eje de sus políticas el apoyo y fomento de la innovación social; en 2010 la Unión Europea publica el programa Innovation Union como uno de los siete pilares de la estrategia 2020. Iniciativas que se analizarán en el epígrafe segundo del texto tomando como base el estudio cualitativo de la documentación producida por los organismos oficiales responsables del diseño y gestión de las políticas de innovación social, con la intención de desentrañar los enfoques predominantes en la praxis de la innovación social y el posible impacto de estos programas gubernamentales en la sociedad, esto es, los objetivos que se persiguen o pretenden conseguir cuando se configura la innovación social en políticas públicas, pues entendemos que desde el ámbito público ha de ejercerse cierto liderazgo para fomentar la innovación social y contribuir a satisfacer las necesidades y demandas sociales de los ciudadanos de una manera diferente, participativa y cooperativa, que puede constituirse en una nueva vía para mejorar la calidad de la democracia a través del empoderamiento ciudadano, cuestiones que, con distinto grado de vinculación jurídica, constituyen mandatos constitucionales en la mayoría de los países.

En tercer lugar, no puede obviarse la existencia de ciertos condicionantes o barreras a la innovación social. La innovación y sus barreras han sido estudiadas básicamente en los campos de la ciencia y la tecnología, teniendo como sujetos principales de estudio el mundo empresarial, las universidades y los centros tecnológicos. En el caso de las instituciones públicas, los factores que limitan la capacidad de innovar han sido poco estudiados principalmente por dos causas; la primera es la reciente incorporación de la innovación social al acervo común de las Administraciones públicas, la segunda el comportamiento organizativo de éstas, que siempre ha tendido más a la reproducción que a la innovación. Aspectos que se desarrollan en el epígrafe tercero de este trabajo, donde se muestra una panorámica de los estudios y encuestas sobre las barreras a la innovación social en el ámbito público.

Finalmente, en los epígrafes cuarto y quinto, se consignan las principales conclusiones de los temas planteados y la bibliografía utilizada para realizar esta investigación.

\section{LAS CONCEPCIONES DE LA INNOVACIÓN SOCIAL}

La innovación social está experimentando desde hace más o menos una década un creciente interés en los sectores académicos, al tiempo que los gobiernos comienzan a integrarla en sus agendas políticas.

La innovación ha sido un factor o elemento que ha estado presente desde los inicios de la revolución industrial, aunque siempre muy vinculado a las concepciones elaboradas desde las disciplinas económicas, con fuerte acento en el mercado y la tecnología, siendo el componente social de la innovación un aspecto incorporado más recientemente.

En el debate sobre la innovación social, como en muchos otros campos del conocimiento, no existe un consenso preciso en torno a su significado en la literatura especializada, existiendo múltiples definiciones elaboradas desde distintas disciplinas científicas. En este sentido, para algunos autores podemos rastrear el concepto de innovación social desde el siglo XIX, especialmente desde la revolución francesa, y desde esta perspectiva histórica se rescata recientemente en respuesta al discurso hegemónico y dominante de la innovación tecnológica (Godin, 2012). Para otros, el concepto lo podemos encontrar en los trabajos de Weber y Schumpeter (Hillier et al, 2004) o más recientemente en la década de los años setenta del siglo pasado (Cloutier, 2003). Para otros autores, la eclosión de la innovación social responde a un intento de paliar las lagunas de las teorías economicistas y tecnocráticas, las cuales obviaban en sus análisis los aspectos de cohesión social y territorial (Moulaert et al, 2010: 21-22).

A esto se unen los efectos de la crisis económica y financiera que irrumpe a partir de 2008, efectos que se han traducido en significativas constricciones del gasto público y el consecuente debilitamiento del estado del bienestar, debilitamiento que ha generado espacios de acción social que el Estado y el mercado no cubren de forma adecuada o simplemente no cubren, por lo que nuevas soluciones y acciones han de ponerse en marcha (Six y Young Fundation, 2010; Howaldt y Schwarz, 2010; Hochgerner, 2011; Arenilla y García, 2013, Conejero 2015).

Estas concepciones de la innovación social, descritas en la tablas 1 y 2, se caracterizan por converger en determinados elementos que tienen en común aunque con distinta intensidad³:

- La satisfacción de necesidades humanas que no están siendo atendidas en ese momento, ya sea por escasez de recursos, por temas de oportunidad política, o no sean percibidas como importantes tanto para el sector privado como para el sector público.

3 Conceptualizaciones que han sido perfiladas principalmente bajo tres enfoques; aquellos provenientes de las disciplinas económicas, los realizados desde de las corrientes de la sociología y, por último, los elaborados al amparo de la ciencia política y de la administración. 
- Ha de producir cambios en las relaciones sociales, especialmente con respecto a la gobernanza, que incrementan los niveles de participación en general, y más concretamente de los grupos más vulnerables de la sociedad.

- Incrementa la capacidad socio-política y el acceso a los recursos necesarios para fomentar el empoderamiento ciudadano.

- Se desarrolla mediante un proceso bottom-up.

Nuestra concepción de la innovación social tiene un carácter más omnicomprensivo y por tanto, consideramos la innovación social como un liderazgo público participado que genera soluciones novedosas (servicios, productos, procesos y modelos) que están orientadas a la resolución de necesidades sociales (con más efectividad que las soluciones tradicionales) y que conllevan, simultáneamente, un cambio en las relaciones sociales y la generación de valor público.

Esta definición contiene los siguientes elementos centrales:

1. Liderazgo público participado: las políticas deben propiciar un ciclo de innovación social participado, ya sea desde el establecimiento de un marco legal, la redefinición compartida del problema social, la cogeneración de ideas, su implementación, evaluación, difusión y réplica.

2. Soluciones novedosas: la innovación social no necesita ser original o única, sino que las soluciones generadas (ideas, productos, servicios, modelos o procesos) sean diferentes a las que ya existían, en caso de que la solución tradicional estuviera presente.

3. Dirigido a la resolución de necesidades sociales: se entiende por necesidades sociales aquellas que si no son satisfechas "pueden causar al ser humano daños y perjuicios graves o sufrimiento social reconocible" (Doyal y Gough, 1994: 71). En este sentido, Doyal y Gough definen las necesidades en básicas e intermedias: las primeras serían aquellas que garantizan las condiciones previas universalizables para la participación social y la persecución de fines propios como la salud física y la autonomía personal. Las segundas son aquellas cuya superación mejora las condiciones básicas y se vertebran en torno a ellas, por ejemplo, su interrelación con el acceso a los distintos servicios públicos (sanidad, educación, sociales, vivienda).

4. Cambio en las relaciones sociales: la innovación social debe propiciar un cambio en las relaciones sociales existentes que modifique la configuración del modelo de gobernanza, especialmente con la inclusión y activa participación de los grupos sociales más vulnerables, marginados e infra-representados. Por tanto, implica un cambio en las relaciones de poder y en la mejora de modelos colaborativos.

5. Mejora la capacidad de la sociedad para actuar: la innovación social potencia los activos y las capacidades de la sociedad aprovechando de una forma más eficiente y efectiva los recursos disponibles a través del empoderamiento ciudadano.

6. Genera valor público: en los sistemas democráticos las instituciones y los procesos representativos deben ser los encargados de crear las condiciones para que los ciudadanos se asocien y decidan colectivamente lo que quieren conseguir juntos. La innovación social ha de materializar esta idea a través de la generación de valor público.

TABLA 1. CONCEPTO DE INNOVACIÓN SOCIAL SEGÚN LAS PRINCIPALES INSTITUCIONES Y CENTROS.

\begin{tabular}{|c|c|}
\hline Definición & Institución \\
\hline $\begin{array}{l}\text { Aquella solución novedosa a un problema social que sea más eficaz, } \\
\text { eficiente, sostenible o simplemente justa que las soluciones actuales, } \\
\text { y cuya aportación de valor se dirija a los intereses de la sociedad en su } \\
\text { conjunto y no a los intereses particulares. }\end{array}$ & $\begin{array}{l}\text { Center for Social Innovation. Univer- } \\
\text { sidad de Stanford. Estados Unidos. }\end{array}$ \\
\hline $\begin{array}{l}\text { Intervención de los protagonistas sociales para modificar las relaciones so- } \\
\text { ciales, transformar un marco de acción o proponer nuevas orientaciones } \\
\text { culturales. Nuevas formas institucionales y organizacionales, nuevas formas } \\
\text { de hacer las cosas, nuevas prácticas sociales, nuevos mecanismos, nuevos } \\
\text { enfoques y nuevos conceptos que producen logros concretos y mejoras. }\end{array}$ & $\begin{array}{l}\text { Social Innovation Center. CRISES. Ca- } \\
\text { nadá. }\end{array}$ \\
\hline $\begin{array}{l}\text { Nuevos conceptos y medidas para solucionar desafíos sociales que son } \\
\text { aceptados y utilizados por los grupos sociales afectados. }\end{array}$ & $\begin{array}{l}\text { Center for Social Innovation. ZSI. } \\
\text { Austria. }\end{array}$ \\
\hline
\end{tabular}




\begin{tabular}{|l|l|}
\hline Nuevas ideas que funcionan para alcanzar los objetivos sociales. & The Young Fundation. Reino Unido. \\
\hline $\begin{array}{l}\text { Introducción de nuevos modelos de negocio y mecanismos basados en } \\
\text { el mercado que proporcionan prosperidad económica, ambiental y so- } \\
\text { cial sostenible. }\end{array}$ & $\begin{array}{l}\text { Social Innovation Center. INSEAD. } \\
\text { Francia. }\end{array}$ \\
\hline $\begin{array}{l}\text { Desarrollo e implementación de nuevas ideas (productos, servicios y } \\
\text { modelos) que satisfacen necesidades y crean nuevas relaciones o cola- } \\
\text { boraciones. }\end{array}$ & Unión Europea. \\
\hline $\begin{array}{l}\text { Desarrollo e implementación de nuevas ideas (productos, servicios y } \\
\text { modelos) que satisfacen necesidades sociales. }\end{array}$ & NESTA. Reino Unido. \\
\hline $\begin{array}{l}\text { Nuevas respuestas a los problemas sociales mediante la identificación } \\
\text { y provisión de nuevos servicios que mejoran la calidad de vida de los } \\
\text { individuos y las comunidades, identificando e implementando nuevos } \\
\text { procesos de integración del mercado laboral, nuevas competencias, } \\
\text { nuevos trabajos, nuevas formas de participación, así como diversos ele- } \\
\text { mentos que mejoran la posición del individuo en el mercado laboral. }\end{array}$ & OCDE. \\
\hline $\begin{array}{l}\text { Un proceso que emerge como parte de un proceso de aprendizaje y prác- } \\
\text { ticas generadoras de conocimiento que tienen lugar en grupo, donde se } \\
\text { ensalzan y articulan diversos modos de conocer el mundo que refuerzan o } \\
\text { generan nuevas competencias en las personas. }\end{array}$ & CEPA. América Latina. \\
\hline $\begin{array}{l}\text { Nuevas ideas (productos, servicios y modelos) que simultáneamente } \\
\text { dan respuesta a las necesidades sociales y crean nuevas relaciones so- } \\
\text { ciales o colaboraciones generando bienestar en la sociedad y al mismo } \\
\text { tiempo produciendo mejoras en su capacidad para actuar. }\end{array}$ & BEPA. Unión Europea. \\
\hline
\end{tabular}

Fuente: Elaboración propia.

TABLA 2. DEFINICIONES DE INNOVACIÓN SOCIAL POR ORDEN CRONOLÓGICO Y SEGÚN AUTORES.

\begin{tabular}{|l|l|}
\hline Definición & Autor \\
\hline $\begin{array}{l}\text { Prácticas más o menos directas que permiten individual o colectivamen- } \\
\text { te hacerse cargo de una necesidad social no satisfecha. }\end{array}$ & Chambon et al (1982: 8) \\
\hline $\begin{array}{l}\text { En el ámbito local descansa en dos pilares: la innovación institucional } \\
\text { (en las relaciones sociales, en la gobernanza, incluida una dinámica de } \\
\text { empoderamiento) y la innovación en la economía social (satisfacción de } \\
\text { necesidades sociales). }\end{array}$ & Moulaert y Nussbaumer (2005: 2071) \\
\hline $\begin{array}{l}\text { La innovación social es un subconjunto de las innovaciones disruptivas } \\
\text { cuyo objetivo primordial es el cambio social. }\end{array}$ & Christensen et al (2006: 96) \\
\hline $\begin{array}{l}\text { Actividades y servicios innovadores que están guiados por el objetivo de } \\
\text { satisfacer necesidades sociales que son predominantemente difundidas } \\
\text { por organizaciones de carácter social. }\end{array}$ & Mulgan et al (2007: 9) \\
\hline $\begin{array}{l}\text { Cambios en la estructura cultural, normativa y regulatoria de la sociedad } \\
\text { que optimiza los recursos colectivos y mejora el desarrollo económico } \\
\text { y social. }\end{array}$ & Heiskala (2007: 59) \\
\hline $\begin{array}{l}\text { Elementos de cambio social que crean nuevas realidades sociales, es } \\
\text { decir, impactan sobre el comportamiento de los individuos o grupos de } \\
\text { una manera muy reconocible con una orientación hacia temas reconoci- } \\
\text { dos que no tienen una motivación económica. }\end{array}$ & Kesselring y Leitner (2008: 28) \\
\hline $\begin{array}{l}\text { Una innovación es social si implica nuevas ideas que tienen el potencial } \\
\text { para mejorar tanto la cantidad como la calidad de vida. }\end{array}$ & Pol and Ville (2009: 882) \\
\hline
\end{tabular}


Son nuevas combinaciones y/o configuraciones de las prácticas sociales en ciertas áreas de acción o contextos sociales, promovida por ciertos actores o constelación de actores de una forma intencional con el objetivo de satisfacer mejor necesidades y problemas.

Son nuevas ideas (productos, servicios y modelos) que simultáneamente satisfacen necesidades sociales (más efectivamente que las alternativas) y que crean nuevas relaciones sociales y de colaboración fomentando las capacidades sociales para la acción.

Nuevas estrategias, conceptos, ideas y organizaciones que responden a necesidades sociales de todo tipo (desde las condiciones de trabajo, la educación para el desarrollo comunitario y la salud) que se extienden y fortalecen a la sociedad civil.

Desarrollo de productos o procesos novedosos que están orientados a la resolución de los problemas más acuciantes de las personas y a la Howaldt y Schwarz (2010: 21) satisfacción de sus principales necesidades, suponen una mejora de las condiciones anteriores así como una transformación del entorno social y las relaciones humanas.

Fuente: Elaboración propia a partir de revisión bibliográfica.

En las definiciones de innovación social subyacen diversas maneras de concebir el papel del Estado, el mercado y la sociedad civil y sus interrelaciones, lo que nos remite al clásico debate entre libertad e igualdad o, en otros términos, a la tensión entre las concepciones de lo público y lo privado de la democracia liberal y los postulados a este respecto de la democracia directa, tensión latente en los tres principales enfoques en los que se encuadran las distintas corrientes científicas como veremos a continuación.

\subsection{El enfoque económico-gerencial}

Una de las primeras aproximaciones al concepto de innovación social es la que se desarrolla desde las disciplinas científicas de carácter económico. El ideario de teóricos como Schumpeter consideraba la innovación como la introducción de nuevos bienes o una nueva cualidad de un bien, la introducción de nuevos métodos de producción, la apertura de nuevos mercados, el descubrimiento de nuevas fuentes de materia prima o un nuevo modelo de organización industrial (Schumpeter, 1934). Así, el economista austriaco señaló dos factores claves para reactivar la recuperación económica: la innovación tecnológica y el papel de los emprendedores. Y el emprendedor es precisamente el que guía los esfuerzos de innovación, siendo la llave que abre la puerta del éxito. Desde esta perspectiva, la innovación social está relacionada con el emprendimiento como motor del cambio social.

Otra perspectiva es la que entiende la innovación social como una nueva vía para satisfacer las necesidades sociales en el que las organizaciones empresariales, con o sin ánimo de lucro, son las encargadas de llevar a la esfera social todas las innovaciones. En este sentido, Peter Drucker en su obra Landmarks for Tomorrow (1957), ya consideraba que la mayoría de los negocios estaban basados en la innovación social. La innovación según este autor no es única ni principalmente una actitud empresarial, sino, sobre todo y especialmente, una actitud social. La innovación puede así ser considerada como un espacio experimental que proporciona libertad de acción tanto para la renovación de los servicios (privados o públicos), como para sus fuerzas principales (el hombre de negocios, la utilidad y el valor). La empresa, puede ser vista como un deseo de llegar al mayor número de consumidores posibles con un comportamiento ético y socialmente responsable. Un espíritu de responsabilidad compartida, sensibilidad y colaboración para ser más efectivos.

Otro autor importante del enfoque económico-gerencial es Jonathan Gershuny. Su tesis sobre las relaciones entre la provisión de servicios de mercado y no mercado visualiza la tendencia hacia el autoservicio y la cooperación, donde los consumidores podían renunciar a la utilidad marginal de un incremento de precio por determinados servicios a favor de otros realizados por ellos mismos o en casa (Gershuny, 1983: 1-4). Postulados que sacaron a luz aspectos innovadores de proceso, denominados "de suministro", a los que no se prestaba suficiente atención en los análisis económicos.

Estas concepciones económico-gerenciales han sido retomadas por los teóricos que han desarrollado o colaborado en la construcción del modelo de innovación social británico como Geoff Mulgan y Charles Leadbeater, poniendo el énfasis en el papel central que los emprendedores sociales tienen en los procesos de innovación social. Leadbeater señala dos motivos por los que es necesario fomentarla. El primero es que la innovación social 
puede "responder más eficazmente a una serie de problemas sociales para los que el Estado de bienestar no está preparado para hacer frente" (Leadbeater, 1997: 12). Y el segundo, porque permite desarrollar modos de innovación empresarial desde las necesidades sociales.

Desde un enfoque gerencial la innovación social se concibe como un proceso que tiene como objetivo contribuir a nuevas soluciones a problemas sociales no resueltos (Lévesque, 2012: 15), fundamentalmente centrado en la innovación organizacional (management y relaciones de coordinación) y los rendimientos progresivos de su institucionalización basados en la eficacia, la eficiencia y la economía.

\subsection{Los enfoques sociales (cultural y ecológico)}

La innovación social entendida como parte de un proceso de innovación cultural y cambio social es la perspectiva predominante en la escuela austriaca liderada por el Centro para la Innovación Social de Austria (ZSI) y liderada por Josef Hochgerner, quien sostiene que "la importancia de la innovación es que está culturalmente integrada", y aboga por una reevaluación de los aspectos culturales de la innovación con el fin de encontrar las mejores soluciones, tanto para la "innovación en la economía y la innovación en la sociedad” (Hochgerner, 2011). La definición acuñada por el ZSI es abstracta y escueta definiendo la innovación social como "nuevos conceptos y medidas para resolver desafíos sociales que son aceptados y utilizados por los grupos sociales afectados" (ZSI, 2008: 7).

Ampliando esta perspectiva, "se refiere a nuevos conceptos, estrategias, iniciativas, productos, procesos y organizaciones que satisfacen las apremiantes necesidades sociales y cambian profundamente las rutinas básicas, redefiniendo los flujos de autoridad o las creencias del sistema social en el que surjan" (Biggs et al, 2010: 3).

En el contexto de los desafíos y las demandas sociales existentes, Hochgerner (2011: 8) aboga por un reexamen de la relación cultural/social de la innovación. Bajo este enfoque, la comprensión de la innovación tiene un significado profundamente arraigado en su contexto cultural, y conduce a una discusión sobre la "culture of innovation" y las "innovation cultures". Estas dos construcciones se refieren a la idea del contexto y conecta con las capacidades de una cultura para fomentar la innovación y los moldes emergentes que dan forma a los principios y procesos de innovación social. También el autor destaca dos deficiencias en los conceptos existentes sobre tecnología:

- Con respecto a las condiciones previas y la variedad de innovaciones, hasta ahora se ha aplicado una insuficiente competencia analítica a la incorporación socio-cultural de las innovaciones tecnológicas. Lo mismo señala con respecto al hecho de que se produzcan innovaciones sociales sin tecnología.

- En cuanto a los resultados de los procesos de innovación, se presta muy poca atención al hecho de que las innovaciones en la tecnología, particularmente cuando resultan ser un gran éxito en los mercados, pueden haber subestimado o simplemente ignorado los efectos negativos en los ámbitos social, cultural o en el medio ambiente.

Por su parte, autores como Pol y Ville (2008: 10) también dibujan una clara diferenciación entre la innovación social y los demás tipos de innovación mediante la identificación de dos acontecimientos:

- La revolución tecnológica de Internet, que se caracteriza por una expansión de las redes e infraestructuras de comunicación.

- El contexto cultural, lo que implica el énfasis en las dimensiones humanas. En este contexto, los bienes culturales se entienden de forma paralela a los servicios.

De los autores arriba citados la discusión se centra en los valores y los sistemas de creencias y prácticas que juegan un papel en el desarrollo de prototipos para la innovación social y su implementación. La cultura tiene una gran influencia en el proceso de innovación social, ya que puede ser una condición o un conjunto de elementos las que definen las características de la propia innovación social. A lo largo de esta argumentación, los procesos culturalmente están arraigados en la innovación social, el foco permanece en valores. Las iniciativas civiles y la acción comunitaria no aparecen como las más relevantes en la conformación de la innovación social de un contexto a otro.

En esta perspectiva, desde la Universidad de Dortmund, Howard y Schwartz (2010: 16) consideran que la “innovación social es una nueva combinación y/o nueva configuración de prácticas sociales en ciertas áreas de acción o contextos sociales, propiciada por ciertos actores o constelación de actores de una forma intencional con el objetivo de satisfacer mejor o dar respuesta a necesidades y problemas sobre las bases de las prácticas establecidas". 
Bajo este enfoque hay que destacar a William F. Ogburn, considerado el primer sociólogo que se ocupa de la innovación social, que separa la misma de la innovación material y sostiene que los cambios en la innovación material generan la aparición de un retraso cultural (cultural lag) que debe ser abordado mediante la innovación social (Ogburn, 1957: 167-168).

También podemos encontrar las aportaciones de Heiskala que define la innovación social como "cambios en la estructura regulatoria, normativa y cultural de la sociedad que potencian los recursos de poder colectivos y mejoran su desempeño económico y social" (Heiskala: 2007: 74).

En resumen, esta concepción de la innovación social ahonda en los contextos geográficos, históricos y políticos de las regiones con patrones culturales específicos de los territorios y los procesos de cambio social como factores relevantes del éxito y el fracaso de las innovaciones. Los roles, las relaciones, las normas y los valores son categorías para el estudio de la innovación social que "permiten innovaciones en el Estado y en la sociedad civil y se convierten objetos de la investigación empírica” (Hochgerner, 2011: 10).

Otra concepción o enfoque de la innovación social desde las ciencias sociales es la que proviene de una aproximación socio-ecológica, que parte del análisis sistémico no sometido a ciclos lineales, donde la innovación social es concebida como un proceso más complejo que opera en los entornos político, social y económico y que ha de influir en aspectos como la distribución de poder y de los recursos o el sistema de creencias y valores, pues el ciclo lineal de análisis oferta/demanda tiene serias limitaciones para explicar la globalidad de elementos que abarca la innovación social. Además, dicho proceso ha de tener durabilidad en el tiempo para que el impacto en el conjunto de la sociedad sea significativo. En este sentido, Christensen et al (2006) definen la innovación social como un subconjunto de las innovaciones disruptivas cuyo objetivo primordial es el cambio social.

Autores como Westley y Antadze dan un paso más allá y consideran que la innovación social está estrechamente conectada con la inclusión social y la resilencia socio-ecológica, argumentando que la capacidad que tiene la sociedad para crear un flujo constante de innovación social, con énfasis en la inclusión de la población vulnerable, es un factor relevante para fomentar dicha resilencia socio-ecológica (Westley y Antadze, 2010: 2-15).

\subsection{El enfoque de la ciencia política y de la administración}

Estamos en presencia del enfoque politológico cuando se conceptualiza la innovación social cómo la búsqueda de una redefinición del bien común, la mejora del bienestar de la población, siendo la tendencia predominante en los trabajos de innovación social y, en nuestra opinión, la concepción más omnicomprensiva pues resulta imprescindible la intervención de las instituciones político-administrativas en esta materia. Es desde la política donde han de conformarse las iniciativas o programas marco de innovación social y ejercerse un liderazgo público ad intra y ad extra, integrando los paradigmas de la Administración pública; a saber, el burocrático, el de la nueva gestión pública y el de gobernanza ${ }^{4}$, siendo el de gobernanza el paradigma que en la actualidad es objeto de mayor atención por la literatura especializada como nuevo modelo de gestión de lo público (Börzel, 1997: 5, Hartley, 2005: 30, Conejero, 2005: 23). Si bien, "el modelo de gobernanza no resuelve el conflicto entre la legitimidad democrática que descansa en la representación y la participación ciudadana, antes bien, puede producir, en distintos grados, la dilución del Estado y de los actores políticos institucionales" (Arenilla, 2011: 77). Además, excepto en el ámbito local, en los restantes gobiernos territoriales su implantación es reducida y circunscrita sólo a una parte de la actividad político-administrativa, a la vista de recientes estudios y encuestas realizados/as a tal efecto, que ponen de manifiesto la dificultad de las instituciones públicas para crear y consolidar redes de gobernanza.

Una perspectiva de análisis importante es la que se deriva de la iniciativa SINGICOM (Social Innovation Governance and Community Building), patrocinada por la Comisión Europea durante los años 2001-2004 y de la que surge el proyecto ALMOLIN (Alternative Model of Local Innovation), liderado por Frank Moulaert y sus colegas de la escuela francesa. Perspectiva que se orienta hacia el desarrollo comunitario sostenible y emerge como una alternativa al desarrollo urbano territorial basado en el mercado (Moulaert y Nussbaurner, 2005).

De esta forma, la innovación social pasa por comprender el papel de la comunidad y los grupos sociales en el desarrollo, donde existe una relación dialógica entre las instituciones económicas y las dinámicas de gobernanza, la sociedad, los modelos de desarrollo territorial y la planificación del territorio. Por tanto, la innovación social aborda "la satisfacción de necesidades básicas y cambios en las relaciones sociales dentro de procesos de empoderamiento social, se refiere a las organizaciones y personas que están afectadas por la privación o falta de

4 Entendemos que la historia de las Administraciones públicas es un proceso acumulativo y, cada vez que surge un paradigma nuevo, éste no ha de desplazar al resto, sino que se ha de reconfigurar la interacción de los mismos. 
calidad en la vida diaria y los servicios" (Moulaert et al, 2010: 10). Su filosofía central no es otra que el logro de la movilización ciudadana y la promoción de la cohesión social a nivel local.

El modelo analítico está estructurado en tres dimensiones: 1) la dimensión de contenido está referida a la satisfacción de necesidades humanas; 2) la dimensión de procesos tiene que ver con los cambios en las relaciones sociales y la gobernanza, y 3 ) la dimensión de empoderamiento está relacionada con el incremento de la capacidad sociopolítica. Por tanto, estamos ante un enfoque basado en valores de solidaridad y reciprocidad, que se entiende como una reacción a los efectos negativos del neoliberalismo, la desregulación y los procesos de privatización (Moulaert y Nussbaumer, 2005).

\subsection{Balance de los enfoques de innovación social}

El enfoque económico descansa sobre la base del emprendedor social como agente principal de la innovación social en la búsqueda de soluciones a demandas no satisfechas por el mercado ni por el Estado. Su aportación reside en ayudar a comprender mejor los ciclos y dinámicas económicas. Sin embargo, su análisis obvia elementos contextuales más complejos que inciden en la innovación social además de focalizar su resultado en términos estrictamente económicos, o en la lógica de beneficios privados, y no tanto en el impacto o valor social. La relación oferta-demanda simplifica en exceso las causas explicativas de los procesos de innovación social.

La perspectiva gerencial supone una profundización del enfoque económico al poner el acento en el valor social que han de tener las iniciativas innovadoras a través de alianzas público-privadas para resolver los problemas sociales. Los emprendedores y las empresas han de configurar compromisos éticos y sociales, espacios de responsabilidad ante la sociedad en la que actúan y donde el beneficio o beneficios de sus actuaciones han de darse con mayor intensidad en el ámbito de lo social que en el ámbito de lo estrictamente privado. No obstante, no tratan los posibles cambios que se puedan dar en las relaciones sociales, ni en los mecanismos de empoderamiento ciudadano y en los cambios institucionales. A nuestro juicio, es una corriente con alto grado de instrumentalidad, orientada a la eficiencia y eficacia de la gestión y a paliar los efectos, más que las causas, de los desajustes o desequilibrios que se producen en los ámbitos de acción de las Administraciones públicas y del mercado privado.

La aportación más notable de la innovación social desde las ciencias sociales es su tratamiento como un proceso sistémico más complejo, a diferencia de los enfoques económico-gerenciales que la conformaban como un proceso lineal, en el que se relacionan un elenco diverso de actores (administraciones públicas, corporaciones, tercer sector y colectivos sociales) con ritmos diferentes que han converger en la creación de un magma continuo de innovación social que permita corregir desajustes en los entornos político-jurídicos, económicos, culturales y sociales mediante la articulación de políticas públicas.

Finalmente, los enfoques de innovación social surgidos de la ciencia política y de la ciencia de la administración ahondan en el análisis de las políticas públicas como mecanismo para buscar soluciones innovadoras que impliquen, además de resolver necesidades sociales concretas, cambios institucionales en programas, legislaciones, en definitiva, cambios en la forma de ejercer la acción de gobierno. Sin embargo, los análisis en estos enfoques se han circunscrito mayoritariamente al ámbito local; la perspectiva multinivel y de gobernanza aún no está suficientemente arraigada en otros niveles territoriales de gobierno para configurar líneas de innovación social de mayor calado.

En definitiva, como señalábamos con anterioridad, estos enfoques reflejan las fricciones existentes en cuanto a los roles que han de desempeñar los actores político-administrativos, los actores del sector privado, los agentes del tercer sector y la ciudadanía en la conformación y el funcionamiento de la cosa pública y su interrelación con la esfera privada. Enfoques que también se reflejan en las políticas de innovación social implementadas por los gobiernos, y que analizaremos para constatar en qué medida dichos programas tienen la capacidad para integrar distintas concepciones de la innovación social o, por el contrario, son poco permeables, optando por una visión más unidimensional o restringida de la innovación social.

\section{EXPERIENCIAS INTERNACIONALES DE INNOVACIÓN SOCIAL EN EL ÁMBITO PÚBLICO}

Tradicionalmente ha sido el sector privado, en concreto el mundo empresarial, el tercer sector y los entornos académico y tecnológico privados, quienes han puesto un mayor énfasis en la innovación, si bien en un primer momento muy enfocado a los modelos lineales de innovación, modelos centrados en la investigación científica, el desarrollo tecnológico y su transferencia a las empresas y el mercado (Echebarría, 2008: 612).

Sin embargo, los enfoques pluralistas de innovación, en los que la dimensión social tiene un peso significativo, están comenzando a introducirse en el sector público, por la potencialidad que la innovación social puede tener en 
la sociedad fortaleciendo valores en torno a la cooperación, la solidaridad o el bien común y en la mejora material de los niveles de bienestar de la población en sus diversos ámbitos como por ejemplo la educación o la salud's.

Por ello, es oportuno analizar las líneas de acción de carácter macro de innovación social a nivel estatal puestas en marcha por los gobiernos. Los casos seleccionados son el programa Big Society del Reino Unido, los programas de la Office of Social Innovation and Civic Participation estadounidense y finalmente, la Innovation Union de la Unión Europea ${ }^{6}$. La aproximación utilizada para analizar los casos seleccionados se realiza utilizando cuatro criterios o descriptores; el primero son los principios orientadores de las estrategias de innovación social, es decir, el discurso en el que centran y definen su modelo; el segundo criterio está referido a los actores participantes, conglomerado principal de agentes que impulsan la innovación social; el tercer criterio es el de políticas y programas más significativos desarrolladas/os, lo que nos da cuenta del grado de institucionalización y diversidad; finalmente, como último criterio, se describen los principales resultados de impacto de las iniciativas con el objeto de ver el grado de desarrollo de los instrumentos medición y evaluación.

\subsection{Big Society. Reino Unido}

\subsubsection{Principios}

En 2010 el gobierno de Reino Unido aprobó un programa a escala nacional denominado Big Society. El programa responde a la necesidad de crear un nuevo discurso de la derecha británica sobre el papel del Estado como contraposición al discurso y programas del partido laborista. Está articulado en tres grandes principios:

1. Empoderamiento de las comunidades locales y de la ciudadanía.

2. Potenciar las empresas y emprendimientos sociales.

3. Fomentar la filantropía en procesos de innovación social.

Para abordar el programa, el Cabinet Office creó en 2010 la Office for Civil Society ${ }^{8}$ como organismo central desde el que pilotarlo, con el objeto de poner en marcha nuevas fórmulas innovadoras de participación y de corresponsabilización con los gobiernos locales, las organizaciones de la sociedad civil, los ciudadanos y el sector empresarial para resolver los problemas sociales con un enfoque transversal, con la implicación de todos los departamentos del gobierno, si bien, bajo esta línea de discurso, también coexisten explícitos objetivos gubernamentales de reducción del gasto público.

\subsubsection{Actores}

Además de la Oficina de la Sociedad Civil adscrita al Cabinet Office, la Social Enterprise UK ha sido otro actor relevante como vertebrador del sector de empresas sociales de Reino Unido e interlocutor del sector público para el fomento de políticas y programas de empresa social como las Empresas de Interés Comunitario9.

Asimismo, otros actores de cierto peso en el asesoramiento, la investigación, el diseño y el desarrollo de aspectos sectoriales de innovación del programa han sido la Young Foundation o el Social Innovation Xchange, constituyéndose esta última en la red por excelencia para el fomento e intercambio de experiencias de innovación social a nivel mundial. Organismos y departamentos del gobierno como NESTA y el Department of Business, Innovation \& Skills, han tenido también una posición importante en el desarrollo y promoción de iniciativas de innovación y en el soporte a organizaciones empresariales y a organizaciones del tercer sector.

5 Así, ha surgido una amplia variedad de organismos y entidades relacionadas con el impulso, la financiación, la implementación, la evaluación e investigación de la innovación social. Nos referimos principalmente, al Center for Social Innovation (Universidad de Stanford) en Estados Unidos, el Social Innovation Center (INSEAD) en Francia, el Social Innovation Centre (CRISES) y el Centre for Social Innovation Research (Universidad de New Brunswick), ambos en Canadá, el Centre for Social Innovation (ZSI), en Austria, NESTA en Reino Unido y el Netherlands Center for Social Innovation en Holanda. En España contamos, entre otros, con el Instituto Nacional de Administración Pública, el Instituto de Innovación Social (ESADE), Innobasque en el País Vasco, el Centro de Ciencias Humanas y Sociales del CSIC o La Noria en la Diputación de Málaga.

6 El caso de Reino Unido ha sido seleccionado por ser un país del entorno europeo y constituir un programa nacional de innovación social que se ha mantenido en el tiempo y cuenta, por tanto, con cierto grado de institucionalización. La iniciativa estadounidense es analizada por ser un modelo macro de ámbito nacional también institucionalizado como en el caso británico, pero con distinto enfoque. El caso del programa de innovación social de la Unión Europea se ha seleccionado por ser un marco de referencia transnacional a medio y largo plazo para los Estados miembros de la UE. La selección no es representativa, pero es bastante orientativa. Por otro lado, tampoco existen demasiadas iniciativas macro de este tipo a nivel nacional. Por ello, se han descartado por ejemplo los casos de Italia y Canadá, orientados básicamente a la economía social en los ámbitos regional y local. También se valoró en un principio incluir el caso de Australia, pero su programa de innovación social está en fase de construcción, teniendo más peso los programas clásicos de innovación tecnológica.

7 https://www.gov.uk/government/uploads/system/uploads/attachment_data/file/78979/building-big-society_0.pdf. (Consulta: 12-052015).

8 http://www.civilsociety.co.uk/directory/company/2765/office_for_civil_society.

9 Comunity Interest Companies, creadas en 2005. 
Finalmente, una pieza clave en el entramado institucional es la Big Society Capital Limited ${ }^{10}$, entidad financiera independiente avalada por el gobierno cuyo objeto es, según su estrategia 2014-2017, catalizar un mercado sostenible de inversión social y profundizar en los mecanismos de inversión social para el asesoramiento y la financiación de las organizaciones del tercer sector en sus distintas etapas de desarrollo ${ }^{11}$. Cuenta además dos organizaciones paralelas para proteger la misión del grupo; el Big Society Trust y la Big Society Foundation.

\subsubsection{Políticas y programas}

A través de la estrategia nacional Big Society se han ido desarrollando distintas iniciativas articuladas bajo los tres principios o grandes líneas de acción mencionados/as:

1. Respecto a los procesos de empoderamiento de las comunidades locales, destaca la iniciativa Localism Bill, que pretende fortalecer la autonomía de los gobiernos locales, mejorar los servicios públicos locales y los mecanismos de rendición de cuentas $^{12}$. Es complementaria con el marco regulatorio de las Empresas de Interés Comunitario (CIC) para responder a las necesidades de las empresas sociales.

2. En lo que atañe a procesos de empoderamiento de la ciudadanía, la Oficina de la Sociedad Civil ha desplegado muchas plataformas para potenciar la participación de los ciudadanos en la vida política a través del programa Take Part ${ }^{13}$.

3. El fortalecimiento de los emprendedores y la empresa social ha sido una de las estrategias en la que más ha incidido el gobierno del Reino Unido al identificarse barreras en este sector como el insuficiente reconocimiento o función social, el desconocimiento de la aportación real del sector a la economía y sus externalidades, el limitado acceso a la financiación o la falta de una política regulatoria integral. Por ello, se ha venido poniendo el acento en su importancia para redefinir las relaciones Estado-Sociedad. Entre los programas o iniciativas destaca Nexters, que ofrece una amplia gama de medidas de apoyo al sector del emprendimiento y la empresa social. Por último, mencionar también los Big Society Awards ${ }^{14}$ como mecanismo de promoción y difusión de aquellas iniciativas más exitosas en el campo de la innovación social.

\subsubsection{Impacto y resultados}

Aún no existe un análisis preciso de medición del impacto social de Big Society. Está centrado en una visión estrictamente cuantitativa, y en esencia economicista, de la actividad y dinámicas de las empresas sociales mediante indicadores de gestión más o menos primarios sobre registro administrativo así como a través indicadores de percepción obtenidos en encuestas periódicas.

Según el informe anual 2013-2014 15 , efectuado por el Comité Regulador de las Empresas de Interés Comunitario (CIC), se ha producido un incremento del $20 \%$ de CIC registradas respecto al año anterior, un $11,2 \%$ de las $\mathrm{CIC}$ se han disuelto y, entre éstas últimas, el $63 \%$ ha operado menos de 3 años. Progresivamente, hay una mayor implantación de esta figura jurídica en el territorio, produciéndose un incremento de la misma en todas las regiones de Reino Unido.

Por otro lado, la encuesta sobre el estado de la empresa social de 2013, realizada por la Social Enterprise Uk ${ }^{16}$, refleja los resultados de percepción siguientes:

- El 38\% de las empresas sociales están fuertemente concentradas en las comunidades más necesitadas del Reino Unido, en comparación con el $12 \%$ en el caso de las pymes tradicionales.

- Las empresas sociales son mucho más propensas incorporar mujeres en funciones de liderazgo que las empresas clásicas. El 38\% de las empresas sociales tienen un líder femenino, mientras que en las pymes el porcentaje es del $19 \%$.

- El $91 \%$ de las empresas sociales tienen al menos una mujer en su equipo de dirección. El 49\% de las principales pymes tiene exclusivamente personal masculino en el ámbito de la dirección.

10 http://www.bigsocietycapital.com/. (Consulta: 15-05-2015).

11 Ha desarrollado una diversificada red de financiación del tercer sector mediante varios mecanismos como fondos generales, fondos especiales, bonos de impacto social y otras operaciones económico-financieras con intermediarios. Véase a este respecto el último informe anual. En línea: http://www.bigsocietycapital.com/sites/default/files/BSC_AR_2013.pdf (Consulta: 15-05-2015).

12 http://services.parliament.uk/bills/2010-12/localism/documents.html (Consulta: 15-05-2015).

13 Actúa como plataforma en proyectos de la comunidad, participación activa y continuada en proyectos de ley, desarrollar planes de barrio, participar en labores de apoyo en la dirección de los colegios, entre otras. https://www.gov.uk/government/get-involved (Consulta: 1505-2015).

14 https://www.gov.uk/government/collections/big-society-awards. (Consulta: 15-05-2015).

15 https://www.gov.uk/government/publications/cic-regulator-annual-report-2013-to-2014. (Consulta: 15-05-2015).

16 http://www.socialenterprise.org.uk/uploads/files/2013/07/the_peoples_business.pdf. (Consulta: 15-05-2015). 
- El $56 \%$ de las empresas sociales ha desarrollado un nuevo producto o servicio en los últimos 12 meses, el $43 \%$ si hablamos de las pymes clásicas.

- El 63\% de las empresas sociales espera aumentar su volumen de negocio en los próximos dos o tres años, en comparación con el $57 \%$ hace dos años. Sólo el $37 \%$ de las pymes espera que su facturación crezca.

- El $38 \%$ de las empresas sociales registraron un aumento de la facturación en comparación con el 29\% de las pymes en el último año.

- En 2011, el 25\% de las empresas sociales que trabajaban principalmente con el sector público mencionó la política de contratación como la principal barrera para su sostenibilidad. En 2013, esa cifra se sitúa en el $34 \%$.

- El $32 \%$ de las empresas sociales afirma que su principal fuente de ingresos proviene del comercio con el público en general.

- El comercio con el sector público va en aumento. Más de la mitad (52\%) de las empresas sociales realizan actividades comerciales con el sector público, el doble que las pymes (26\%).

- La cantidad media de financiación solicitada por empresa social era $58.000 €$, por debajo de los umbrales mínimos de muchos instrumentos especiales de inversión social. No obstante lo anterior, la financiación es considerada como la principal barrera de las empresas sociales para su sostenibilidad.

Al margen de estas fuentes de información, se está trabajando además en la construcción de índices sintéticos que midan el impacto social, el bienestar producido en los beneficiarios y su entorno por las intervenciones en materia de innovación social. En este sentido, está en fase piloto el índice Wellbeing and Resilience Measure (WARM) para medir el impacto de dichas intervenciones en las comunidades locales (Ngumi y Bacon, 2010) y valorar el grado de cumplimiento de los objetivos de Big Society.

Se podría valorar el caso del Reino Unido como un ejemplo que ha considerado la innovación social como una política a largo plazo, en la que predomina el foco sobre el papel las empresas sociales para resolver las ineficacias o fallos del sector público, claramente orientada a las tesis gerenciales de mercado. No ha de olvidarse, que el Reino Unido es un país donde la Nueva Gestión Pública, como modelo de gestión político-administrativa, está fuertemente interiorizada en las Administraciones públicas británicas desde hace varias décadas.

\subsection{Social Innovation and Civic Participation. Estados Unidos}

\subsubsection{Principios}

La creación en 2009 de la Oficina de Innovación Social y Participación Ciudadana (OSICP, en sus siglas en inglés), ubicada en el Consejo de Política Nacional ${ }^{17}$, definió su orientación en hacer negocios de manera diferente mediante la promoción del servicio público como una solución y una manera de desarrollar el liderazgo comunitario, el aumento de la inversión en soluciones comunitarias innovadoras basadas en resultados y en el despliegue de nuevos modelos de asociación. En este sentido, sus principios de actuación son:

- Importancia en los resultados. Los programas y organizaciones han de ser medidos/as y evaluados/as para invertir en las soluciones más eficaces.

- Soluciones de abajo hacia arriba (Bottom-up). Desarrollo de iniciativas viables propuestas por las comunidades locales y la ciudadanía frente al tradicional modo normativo de actuación de gobiernos y administraciones en el diseño, implementación y evaluación de programas y necesidades.

- Ampliación de la participación. Invertir en la búsqueda de viveros de liderazgo social a futuro para revitalizar la vida política y social.

- Responsabilidad compartida. Involucrar a los distintos actores del sector social, empresarial y a la ciudadanía en la actividad de gobierno a través de los distintos programas y políticas públicas.

Sobre estos principios focalizan su actividad en tres áreas de actuación:

- Incorporar a las comunidades en el desarrollo y mejora de los servicios públicos.

- Aumentar la inversión en soluciones innovadoras basadas en resultados medibles, como los fondos de innovación, premios y otras estructuras del mercado de capital social para construir un gobierno más eficaz y eliminar las distintas barreras a la innovación en los ámbitos político, social y económico.

17 https://www.whitehouse.gov/administration/eop/sicp (Consulta: 15-05-2015). 
- Desarrollar innovadores modelos de colaboración con distintos agentes para solventar problemas comunes de mayor impacto.

\subsubsection{Actores}

Existe una amplia red de actores que participan en el programa federal de innovación social estadounidense. Además de la OSICP como organismo gubernamental vertebrador y coordinador, está la Corporation for National and Community Service ${ }^{18}$ (CNCS) como agencia federal principal para el despliegue de la mayoría de los programas de participación de ciudadanos y de comunidades en los servicios públicos estatales y federales.

El enfoque de la estrategia de innovación social es multisectorial, participando en él todos los departamentos federales directamente o través de agencias adscritas, como por ejemplo en materia de medición y resultados, al ser una prioridad de gobierno medir sus objetivos, donde existe un grupo interdepartamental liderado por la Office Management and Budget de la Casa Blanca. Los principales destinatarios de los programas son las comunidades locales, ciudadanos, el tercer sector y las empresas sociales,

\subsubsection{Políticas y programas}

Desde el gobierno federal se aprobó la Ley Serve America para regular la participación de ciudadanos y de comunidades en los servicios públicos a través de programas como AmeriCorps, vinculado a los servicios a la comunidad, la implantación de premios para la difusión y promoción de la innovación social. También la CNCS ha lanzado la plataforma Serve.gov, que proporciona herramientas para que los ciudadanos puedan encontrar proyectos de servicio en sus comunidades, desarrollar sus propios proyectos o la promoción de sus trabajos con los medios de comunicación.

Como soporte central de la financiación de la estrategia de innovación del gobierno federal se habilitó una dotación presupuestaria de 1.149 millones de dólares y se aprobó otra norma, la Ley de Recuperación y Reinversión (American Recovery and Reinvestment Act) que aportó 200 millones para apoyar a más de los 15.000 miembros de AmeriCorps que sirven en las comunidades económicamente más deprimidas.

Dentro del bloque centrado en nuevas soluciones innovadoras, hay que destacar el Fondo de Innovación Social ${ }^{19}$, como instrumento financiero para dar cobertura a las comunidades en programas de salud, juventud y oportunidades económicas.

Por otra parte, los premios y los retos se perfilan con criterios de competitividad para que las personas, comunidades, entidades gubernamentales, empresas u organizaciones sin fines de lucro se orienten al logro de los objetivos definidos en un marco de tiempo explícitamente delimitado. Se introducen también incentivos que pueden revestir la forma de recompensas monetarias o recompensas no monetarias, como el reconocimiento de los mejores modelos, el aumento de la participación, o el avance en una determinada área de necesidad. En este sentido, numerosos departamentos y agencias federales han ido estableciendo su modalidad de premios, como por ejemplo el i6 Challenge en el Departamento de Comercio.

La tercera línea de acción, la conformación de parternariados público-privados, está basado en la búsqueda de convergencia de intereses entre el gobierno y el sector no gubernamental. Requiere de riesgo compartido en inversión (directa o indirecta) así como de proporcionales recompensas e incentivos. Se han desarrollado programas como:

- Educate for innovate. Campaña para mejorar la participación y el rendimiento de los estudiantes de Estados Unidos en materia de ciencia, tecnología, ingeniería y matemáticas (STEM).

- Let's Move. Campaña que trabaja en asociación con las principales fundaciones, organizaciones no lucrativas y el sector privado a través de la Asociación para una América más saludable con el objetivo de ayudar a erradicar la obesidad infantil en una generación.

- Text4Baby. Asociación público-privada innovadora que mediante sistema de mensajería sms, semanalmente ofrecen a las mujeres embarazadas y a las nuevas madres información para ayudar a cuidar de su salud y dar a sus bebés el mejor comienzo posible en la vida.

\subsubsection{Impacto y resultados}

Los resultados más significativos son el incremento de los miembros activos registrados en el programa AmeriCorps, 75.000 miembros nuevos cada año. Al Premio de Educación Segal AmeriCorps se le otorga el nivel máximo de prestigio. Se mejoran las opciones de servicio para los estadounidenses con experiencia ampliando la edad y elegibilidad de ingresos para Abuelos Adoptivos y compañeros mayores, y se crea un programa de Becarios de

18 http://www.nationalservice.gov/ (Consulta: 15-05-2015).

19 http://www.whitehouse.gov/administration/eop/sicp/initiatives/social-innovation-fund. (Consulta: 15-05-2015).

GESTIÓN Y ANÁLISIS DE POLÍTICAS PÚBLICAS, Nueva Época, - N.º 15, enero-junio 2016 - ISSN: 1989-8991 - DOI: 10.24965/gapp.voi15.10310 
plata, según el cual las personas mayores de 55 años que realizan 350 horas de servicio reciben una beca educativa de mil dólares.

Se ha fortalecido la infraestructura de capital social a través de la creación de dos programas; el programa de Voluntariado para ayudar a reclutar y administrar voluntarios de apoyo, y el programa de Desarrollo de Capacidades para mejorar el rendimiento de las organizaciones del tercer sector en las comunidades con escasos recursos. Además, a través de la plataforma Serve.org, se han ofrecido 250.000 oportunidades a los ciudadanos para servir en las comunidades.

Por otra parte, en materia presupuestaria, se ha mantenido constante la inversión económica de los distintos fondos de innovación social para mejorar el acceso a la financiación de los sectores no gubernamental y empresarial.

En lo que respecta a cuestiones de medición y evaluación, la Administración federal estadounidense ha realizado grandes esfuerzos, en concreto, ha desarrollado estándares para medir la gestión del Fondo de Innovación Social (FIS), alineados con el Fondo de Inversión en Innovación (FII) del Departamento de Educación. Se ha establecido un grupo de trabajo de evaluación interinstitucional y se ha puesto en marcha una iniciativa piloto de evaluación voluntaria de las agencias federales. Además, se han publicado las primeras mediciones de rendimiento estandarizados para los programas nacionales de servicios de la CNCS.

Mencionar finalmente the Open Government Initiative ${ }^{20}$, cuya finalidad principal es mejorar la transparencia, la participación ciudadana y la colaboración intragubernamental, vinculándola con la medición de la innovación social, aspecto importante que no está suficientemente desarrollado en otros países.

La experiencia del gobierno federal estadounidense destaca por su enfoque muy ligado al tercer sector social y el fortalecimiento de la sociedad civil, pero también a valores como la responsabilidad compartida y la rendición de cuentas. Además, iniciativas como Social Innovation Fund es una de las primeras grandes estrategias de innovación social a nivel nacional, que nace desde el gobierno central y que busca fomentar la innovación social incorporando al sector privado, además de fortalecer organizaciones locales intermediarias.

\subsection{Innovation Union. Unión Europea}

\subsubsection{Principios}

La Unión Europea pone en marcha su estrategia “Unión por la Innovación: convertir las ideas en empleo, crecimiento ecológico y progreso social”, publicada en octubre de 2010 (CE 2010, COM 546 final), como uno de los siete pilares de la estrategia 2020 de la UE. En marzo de 2011 se impulsa la Plataforma Europea de Innovación Social. El enfoque que la Comisión Europea adopta de la innovación social se sintetiza en la introducción de la estrategia Unión por la Innovación, así “la innovación se ha colocado en el centro de la estrategia Europa 2020 para el crecimiento y el empleo. Con más de treinta puntos de acción, la Unión por la Innovación tiene como objetivo mejorar las condiciones y el acceso a la financiación para la investigación y la innovación en Europa, para garantizar que las ideas innovadoras puedan convertirse en productos y servicios que generen crecimiento y empleo" (European Commission, 2011). La Unión Europea define la innovación social como "nuevas ideas para hacer frente a las necesidades apremiantes e insatisfechas. De manera sencilla, la describimos como las innovaciones que son sociales tanto en sus objetivos como en sus medios. Las innovaciones sociales son las nuevas ideas (productos, servicios y modelos) que, de manera simultánea, satisfacen las necesidades sociales (con mayor eficacia que las alternativas) y crean nuevas relaciones sociales o colaboraciones", definición en la línea británica establecida en el Open Book of Social Innovation, elaborado por la Fundación Nesta en 2010.

El concepto adoptado por la Comisión Europea concibe la innovación social como un equivalente para mejorar la aplicación y la evaluación de resultados. Para explicar este nuevo enfoque, las instituciones involucradas en los procesos de toma de decisiones han adoptado el concepto de experimentación social, esto es, encontrar formas de revitalizar la política, haciéndola más eficiente, más eficaz y mejor adaptada a las nuevas necesidades sociales, ya que se buscan nuevas formas de luchar contra la pobreza y la exclusión social en el contexto europeo, cambiando su regulación y marcos de financiación. Los métodos participativos y de colaboración, co-diseño, cocreación, son argumentos presentes en el discurso de la innovación social, aunque aún poco desarrollados.

\subsubsection{Actores}

Al ser la estrategia de innovación social de la Unión Europea una estrategia transnacional, intervienen en ella un gran elenco de actores. En principio, la iniciativa está liderada por la Dirección General de Empresa e Industria,

20 http://www.whitehouse.gov/open (Consulta: 15-05-2015). 
lo que da cuenta de que las prioridades están aglutinadas en torno al crecimiento, la competitividad y el empleo, aunque la transversalidad de los programas exige un alto componente de coordinación con el resto de departamentos así como con organismos públicos europeos y agencias colaboradoras. Los destinatarios principales de los programas son los emprendedores sociales.

\subsubsection{Políticas y programas}

Los programas de innovación social desplegados por la Unión Europea están centrados en siete áreas:

1. Redes. A través de la iniciativa Social Innovation Europe ${ }^{21}$, puesta en marcha en 2011, plataforma para compartir experiencias y fomentar el trabajo colaborativo.

2. Competencia. En este área destaca el Concurso Europeo de Innovación Social ${ }^{22}$ que se celebra cada año para apoyar directamente a las nuevas soluciones y crear conciencia sobre la innovación social, al margen de convocatorias similares que realizan otros departamentos comunitarios.

3. Financiación europea. Esta materia está básicamente asociada al Programa de Empleo e Innovación Social $^{23}$ (EaSI), en particular en el marco del Instrumento PYME que también está abierto a las empresas sociales.

4. Finanzas. Este aspecto es desarrollado por un programa cuyo objeto es compartir información sobre ayuda financiera disponible, que puede ser movilizada desde las organizaciones del sector público, fundaciones o inversores privados. A tal efecto se suelen publicar distintos informes sobre financiación de impacto social.

5. Empresa social. Se articula la Iniciativa Social Empresarial ${ }^{24}$, que tiene por finalidad el impulsar la creación de un entorno favorable para el desarrollo de las empresas sociales en Europa.

6. Incubación. Área que pone el foco en el apoyo a las estructuras de incubación para la innovación social en Europa, desplegando en octubre de 2013 los proyectos Transition ${ }^{25}$ y Benisi ${ }^{26}$.

7. Ampliación y difusión de la innovación social. Este ámbito de actuación está enfocado al desarrollo de estrategias para el crecimiento y la difusión de la innovación desde la perspectiva de cambio sistémico (Murray, Caulier y Mulgan, 2010: 107-123).

\subsubsection{Impacto y resultados}

Los resultados más significativos están referidos al incremento del emprendimiento social. El impacto del conjunto de programas de innovación social en la sociedad y la economía aún es incierto por su breve recorrido. Al estar asociados a los objetivos macro de la Estrategia europea 2020, es difícil estimar en qué medida la innovación social ha generado resultados positivos en términos de competitividad, educación, inclusión social, empleo y medio ambiente.

No obstante, se está trabajando en distintos ámbitos para desarrollar constructos de medición de lo social como la Social Innovation Scoreboard ${ }^{27}$ (European Commission, 2012b) y de sistemas de indicadores para mensurar el impacto social vinculados a la actividad de las empresas sociales y, en menor medida, del tercer sector (GECES, 2013). La asunción de un modelo de medición a través de indicadores respalda y orienta la toma de decisiones enfocada a la formulación de políticas públicas. El establecimiento de indicadores mejora la concreción de los objetivos que persigue la innovación social y los hace más entendibles. Un presupuesto básico de la concreción de objetivos es que cuanta más claridad exista en la definición de los mismos, más fácil será la definición e identificación de indicadores para su medición.

En definitiva, el desarrollo de un sistema sólido de indicadores contribuye a la mejora de la legitimidad de la acción pública y permite valorar en qué medida se ha creado valor social. Legitimando, a su vez, los programas de innovación social no solo para los grupos que son destinatarios de los mismos sino con respecto a la sociedad en su conjunto (Schmitz et al, 2013: 4).

\subsection{Balance de los programas gubernamentales de innovación social}

El modelo de innovación social de Reino Unido es predominantemente gerencial, muy enfocado a la empresa social. Si bien ha tratado de forma sistemática el emprendimiento social aprobando nuevos marcos reguladores

21 https://webgate.ec.europa.eu/socialinnovationeurope/ (Consulta:11-05-2015).

22 http://ec.europa.eu/enterprise/policies/innovation/policy/social-innovation/competition/index_en.htm (Consulta: 11-05-2015).

23 http://ec.europa.eu/social/main.jsp?catld=1081 (Consulta: 11-05-2015).

24 http://ec.europa.eu/internal_market/social_business/index_en.htm (Consulta: 11-05-2015).

25 http://transitionproject.eu/(Consulta: 11-05-2015).

26 http://www.benisi.eu/ (Consulta: 11-05-2015).

27 Constructo que únicamente estaba orientado a medir la innovación tecnológica, como era el caso de la Regional Innovation ScoreBoard. 
y mejorando los existentes, los aspectos de cambio institucional en las relaciones Estado-Sociedad están básicamente en el plano discursivo pero sin incidencia significativa en la praxis y en los roles de los distintos actores. La innovación social es concebida a modo de fases lineales para intentar paliar diversas problemáticas de forma incremental tanto por parte de las empresas sociales como por agentes destacados del sistema o modelo implantado.

El modelo británico no ha puesto suficiente acento en la medición del valor social generado, a pesar de ser dicho valor un factor crítico para evaluar la viabilidad del programa gubernamental de innovación social y su posible apertura a una concepción más amplia de innovación social. Tampoco existen aún datos relevantes sobre la incidencia de los programas de innovación social sobre la autonomía local y el empoderamiento ciudadano.

La estrategia federal de innovación social en Estados Unidos está muy enfocada en el tercer sector social, las comunidades locales y menor medida, aunque también es relevante, en la empresa social. Es un modelo que va más allá del modelo gerencial, es más aperturista al cambio institucional, a la responsabilidad compartida de organizaciones y ciudadanos y a la transparencia. El impacto social y la eficiencia del gasto es un referente crítico del sistema, por lo que es el país que está desarrollando los mejores instrumentos de medición y evaluación. No obstante, al igual que en los casos británico y de la Unión Europea, es aún relativamente pronto para hacer valoraciones globales de la estrategia de innovación social.

La iniciativa de innovación social de la Unión Europea es más ambigua, quizás, entre otras razones, por las dimensiones de su ámbito geográfico, las especificidades de su funcionamiento y la variedad de objetivos. Sin embargo, los objetivos de competitividad y empleo son los prioritarios, por lo que los programas de empresa social tienen un mayor peso que los programas de empoderamiento ciudadano y del tercer sector. En lo concerniente a materia de seguimiento y evaluación, se están realizando esfuerzos de cierto relieve para diseñar e implantar modelos de medición de la innovación social.

TABLA 3. CARACTERÍSTICAS DE LOS PROGRAMAS NACIONALES DE INNOVACIÓN SOCIAL

\begin{tabular}{|c|c|c|c|}
\hline $\begin{array}{l}\text { Programa marco } \\
\text { deinnovación } \\
\text { social }\end{array}$ & Big Society. (Reino Unido) & $\begin{array}{l}\text { Social Innovation and } \\
\text { Civic Participation } \\
\text { (Estados Unidos) }\end{array}$ & $\begin{array}{l}\text { Innovation Union. (Unión } \\
\text { Europea) }\end{array}$ \\
\hline $\begin{array}{l}\text { Definición de la } \\
\text { innovación social }\end{array}$ & $\begin{array}{l}\text { Nuevas ideas (productos, } \\
\text { servicios y modelos) que } \\
\text { satisfacen las necesidades } \\
\text { sociales (con mayor eficacia que } \\
\text { las alternativas) y que a su vez } \\
\text { crean nuevas relaciones sociales } \\
\text { o colaboraciones. }\end{array}$ & $\begin{array}{l}\text { Nuevas formas } \\
\text { de resolver viejos } \\
\text { problemas en aras del } \\
\text { interés público. }\end{array}$ & $\begin{array}{l}\text { Nuevas ideas (productos, } \\
\text { servicios y modelos) que, } \\
\text { de manera simultánea, } \\
\text { satisfacen las necesidades } \\
\text { sociales (con mayor eficacia } \\
\text { que las alternativas) y crean } \\
\text { nuevas relaciones sociales } \\
\text { o colaboraciones. }\end{array}$ \\
\hline $\begin{array}{l}\text { Enfoque } \\
\text { predominante }\end{array}$ & Económico-gerencial. & $\begin{array}{l}\text { Gerencial/Ciencia } \\
\text { política. }\end{array}$ & Económico-gerencial. \\
\hline Finalidad/es & $\begin{array}{l}\text { Satisfacer demandas sociales a } \\
\text { través de los actores principales. } \\
\text { Empoderamiento de las } \\
\text { comunidades locales. }\end{array}$ & $\begin{array}{l}\text { Satisfacer demandas } \\
\text { sociales a través de los } \\
\text { actores principales. } \\
\text { Empoderamiento de las } \\
\text { comunidades locales. }\end{array}$ & $\begin{array}{l}\text { Competitividad, } \\
\text { satisfacer demandas } \\
\text { sociales a través de los } \\
\text { actores principales. }\end{array}$ \\
\hline $\begin{array}{l}\text { Actor/es } \\
\text { principal/es }\end{array}$ & $\begin{array}{l}\text { Emprendedores sociales, } \\
\text { empresas sociales. }\end{array}$ & $\begin{array}{l}\text { Tercer sector, } \\
\text { comunidades locales, } \\
\text { empresas sociales. }\end{array}$ & $\begin{array}{l}\text { Emprendedores sociales, } \\
\text { empresas sociales. }\end{array}$ \\
\hline $\begin{array}{l}\text { Impacto } \\
\text { predominante }\end{array}$ & $\begin{array}{l}\text { Evolución de las empresas de } \\
\text { interés comunitario. }\end{array}$ & $\begin{array}{l}\text { Evolución de la actividad } \\
\text { del tercer sector, el } \\
\text { voluntariado y las } \\
\text { comunidades locales. }\end{array}$ & $\begin{array}{l}\text { Evolución del } \\
\text { emprendimiento social. }\end{array}$ \\
\hline $\begin{array}{l}\text { Sistemas de } \\
\text { medición }\end{array}$ & En fase de construcción. & $\begin{array}{l}\text { En fase de } \\
\text { implementación. }\end{array}$ & En fase de construcción. \\
\hline
\end{tabular}

Fuente: Elaboración propia. 


\section{BARRERAS A LA INNOVACIÓN SOCIAL}

El mayor o menor grado de implementación de la innovación social en las estructuras político-administrativas de los Estados se debe a la existencia de diversas barreras u obstáculos recurrentes. En la literatura existente sobre las barreras a la innovación social en el ámbito público de carácter internacional, se señala con carácter general que aún no existen suficientes estudios para explicar en profundidad este fenómeno (European Commission, 2012: 5). Las distintas publicaciones hacen referencia a la existencia de un conjunto de barreras más o menos comunes pero adolecen de análisis de mayor calado que ayuden a clarificar o desentrañar ya sea la correlación entre dichas barreras o el grado de intensidad con la que inciden en función de contextos concretos (territoriales, culturales, materiales).

En una primera aproximación se ponen de manifiesto dos tipos de barreras que están interrelacionadas; las barreras estructurales, entendidas como las que se relacionan con la complejidad e incertidumbre en la que se desenvuelven los procesos sociales y los innovadores sociales en su entorno (social, político, tecnológico, etc.) y, las barreras de "agencia", que se generan por la interacción de individuos y actores que participan en los procesos de innovación social (European Commission, 2012b: 60).

Barreras que pueden clasificarse en tres bloques materiales:

1. Barreras relacionadas con la organización (recursos humanos, medios, liderazgo, cultura organizativa, modelo de gestión).

2. Barreras relacionadas con la economía (financiación interna y externa).

3. Barreras relacionadas con el entorno (redes y cooperación, acceso al conocimiento, establecimiento de buenas prácticas y referentes).

Otro estudio sobre barreras a la innovación social en el ámbito público, en este caso referido a España, circunscrito geográficamente a la Comunidad autónoma del País Vasco, (Grupo Q-EPEA, 2009: 7-12), identificó seis categorías a las que se corresponden diversas barreras críticas:

- Ciudadanía: Dificultades para establecer redes de cooperación con actores y deficiencias de los mecanismos de participación.

- Personas (empleados públicos): Aversión al cambio ${ }^{28}$, falta de liderazgo, inadecuada gestión de recursos humanos.

- Política: La indefinición de los espacios de la política y la administración ${ }^{29}$, visión de objetivos a corto plazo, poca tendencia a pactos viables de las distintas fuerzas políticas.

- Gestión y estructura organizativa: Predominio excesivo del modelo de gestión burocrática en el funcionamiento de las Administraciones públicas y su incidencia en la cultura organizativa y la mentalidad de los empleados públicos.

- Nuevas tecnologías: Poca capacitación del personal sobre las capacidades de las TIC's.

- Otros factores: Poca conciencia sobre la necesidad de innovación, ausencia de referentes, deficiente difusión de la innovación.

Los resultados obtenidos coinciden a grandes rasgos con el estudio mencionado en primer lugar, en lo relativo a las disfunciones o patologías clásicas de las organizaciones político-administrativas ${ }^{30}$, en materias como la definición de su misión y la relación con sus entornos, los conflictos entre política y gestión, las dinámicas organizativas y de cultura o la colaboración público-privada ${ }^{31}$.

28 Un estudio elaborado por la Oficina Nacional de Auditoria en el Reino Unido puso de manifiesto las reticencias de los servidores públicos para asumir actitudes o comportamientos que impliquen riesgo. Con carácter general las metas, los objetivos de desempeño y las dinámicas presupuestarias dejan poco espacio para la innovación. Los servidores públicos se muestran reacios a asumir cambios o innovaciones sin una comprensión clara de lo que se persigue con los procesos de innovación y de cómo éstos se relacionan con los objetivos de la organización. Mensajes más claros acerca de por qué es necesaria la innovación y lo que esperan del personal ayudaría a superar esta barrera (NAO; 2009:7).

29 Tradicionalmente, ha existido una importante reticencia por parte del sector público para asumir retos innovadores por el escrutinio público que por parte de la oposición, los medios de comunicación o la opinión pública sufren las decisiones que toman sus dirigentes y las graves consecuencias que la obtención de resultados negativos tienen para los gestores públicos en el supuesto de que las decisiones tomadas no fuesen las idóneas (Thenint, 2010: 19).

30 Una barrera clave es la relativa a las cuestiones de cambio de cultura o gestión del cambio y su correlación con las mentalidades. El incidir en esta barrera podría hacer desaparecer muchas otras o, en su caso, reducirlas a umbrales aceptables. En este sentido también se posicionan (Halvorsen et al, 2005: 9, Nauta y Kasbergen, 2009: 20).

31 En un informe elaborado por MaRS para la provincia de Ontario en Canadá, se identificó como uno de los problemas y obstáculos a la innovación social la falta de transparencia en la disposición de información y la falta de comunicación por parte de la Administración pública 
En definitiva, se evidencia la ausencia de modelos referentes para la construcción de modelos de innovación social en lo público, no únicamente para diseñar y poner en práctica programas o estrategias de innovación, también para su análisis y evaluación.

\section{CONCLUSIONES}

Aunque existan diferentes perspectivas en la conceptualización de la innovación social su incorporación a las políticas públicas es muy relevante porque puede contribuir a satisfacer las necesidades y demandas sociales de los ciudadanos de una manera diferente, efectiva, participativa y cooperativa. Se abre así una nueva vía para mejorar la calidad de la democracia a través del empoderamiento ciudadano.

Las insuficiencias que han mostrado los modelos burocráticos y de la Nueva Gestión Pública para hacer frente a nuevos y complejos problemas sociales obliga al sector público a profundizar en modelos de gobierno abierto en el que han de converger la visión y las ideas que los diferentes actores aportan en la interpretación de la realidad social. Las fórmulas de la gobernanza colaborativa constituyen un nuevo paradigma de gestión a través del cual se pueden realizar aportaciones innovadoras participadas y traducirlas en actuaciones para mejorar la calidad de la democracia y sus instituciones, aunque la introducción de elementos más cualificados de participación de los distintos actores siempre han respetar el principio de representación política.

Sin embargo, los modelos de innovación social implantados por los gobiernos están fuertemente ideologizados, fruto de la tensión siempre presente en el binomio liberalismo/republicanismo y sus visiones sobre la función del Estado, del mercado y la sociedad en la construcción del bien común. Predomina el enfoque gerencial en los programas nacionales de innovación social, mientras que los enfoques de innovación social más cercanos a la ciencia política y de la administración son aplicados mayoritariamente en proyectos innovadores en contextos locales. A ello han de sumarse, al menos en el contexto europeo, las directrices políticas y acuerdos emanadas/ os desde Bruselas, priorizando principios como la estabilidad por encima de otros principios como la igualdad, o posibilitando cierta quiebra de principios como la libertad de circulación. Todo ello en una coyuntura de fuertes restricciones presupuestarias, lo que supone una seria limitación para las políticas de innovación social pluralistas. En este sentido, la implementación del conjunto de los programas analizados no parece haber tenido un efecto cierto en lo que concierne a cambios institucionales significativos y al empoderamiento de la ciudadanía y organizaciones del tercer sector en el diseño, participación y seguimiento de las políticas y programas públicos, excepto, quizás, en el caso norteamericano y, con carácter general, en determinadas iniciativas a nivel local para el conjunto de países seleccionados en el estudio.

A estas cuestiones no son ajenas las barreras existentes en la innovación social, donde las barreras referidas al cambio de cultura organizativa y el modelo de gestión son las inciden con mayor intensidad como obstáculos para innovar en el ámbito público y mediatizan al resto de barreras, sean estructurales o de carácter instrumental, lo que pone de manifiesto la necesidad de un cambio de mentalidad por parte de las autoridades públicas.

Finalmente, consideramos que los modelos públicos de innovación social deberían tender con el tiempo a una concepción o formato menos ideologizado, una vez que el carácter emergente de la innovación social se incorpore o consolide como una función habitual en las estructuras político-administrativas, pues lo primordial es establecer estrategias o marcos innovadores estables en los que confluyan los distintos elementos que conforman la innovación social.

\section{BIBLIOGRAFÍA}

Arenilla, M. (2011), "Marco teórico actual de la Administración Pública”, en M. Arenilla, dir; Crisis y reforma de la Administración Pública. La Coruña: Editorial Netbiblo.

Arenilla, M. y García, R. (2013), Innovación Social. La integración social en la Administración Pública, La Coruña: Editorial Netbiblo. DOI: 10.4272/978-84-15562-40-5.

BEPA (2010), “Empowering people, driving change: social innovation in the European Union”, Brussels. En línea: http://www.net4society.eu/_media/Social_innovation_europe.pdf. (Consulta: 14-05-2015).

Biggs, R, Westley, F.R. y Carpenter, S. R. (2010), "Navigating the back loop: fostering social innovation and transformation in ecosystem management", Ecology and Society, 15 (2). En línea: http://www. ecologyandsociety.org/vol15/iss2/art9/. (Consulta: 10-05-2015).

Börzel, T. (1997), "¿Qué tiene de especial el concepto de policy networks? Explorando el concepto y su utilidad para el estudio de la gobernación europea”, Revista de Redes Sociales. En línea: http://revista-redes.rediris.es/ webredes/textos/policynet.pdf (Consulta 10-05-2015).

para que las organizaciones sociales pudieran acceder a programas o diferentes ayudas vinculados a la innovación social y gestionadas desde el gobierno (MaRS, 2011: 7). También véase (BEPA, 2010: 105). 
Chambon, J.L. David, A. y Devevey, J. M. (1982), Les innovations sociales. Paris: Presses Universitaires de France.

Christensen, C. M., Baumann, H. Ruggles, R, y Sadtler, T.M. (2006), "Disruptive innovation for social change". Harvard Business Review, 84(12), pp. 94-101.

Cloutier, J. (2003), “Qu'est-ce que l'innovation sociale?”, Collection Études Théoriques No ET0314, CRISES.

Conejero, E. (2015), "Sinergia entre las organizaciones públicas y privadas: nuevos modelos de gobernanza para la provisión de bienes y servicios públicos”, en M. Arenilla y R, García, dirs; Innovación social: claves y casos. La Coruña: Consejo social de la Universidad de Coruña.

Conejero, E. (2005), "Globalización, gobernanza local y democracia participativa". Cuadernos Constitucionales de la Cátedra Fadrique Furió Ceriol, 52/53, pp. 13-31.

Christensen, C. M., et al (2006), "Disruptive innovation for social change”. Harvard Business Review, 84(12), pp. 94-101.

Echebarría, J. (2008), “El Manual de Oslo y la innovación social”, Revista Arbor, Volumen CLXXXIV (732), julioagosto Madrid. DOI: 10.3989/arbor.2008.i732.210.

European Commission. (2011), “Innovation Union”, Brussels. En línea: http://ec.europa.eu/research/innovationunion/index en.cfm. (Consulta: 11-05-2015).

European Comission. (2012), “Barriers to Social Innovation, FP 7 Project TEPSIE”. Brussels. En línea: http://www. tepsie.eu/images/documents/tepsie.d3.1barrierstosocialinnovation.pdf (Consulta: 14-05-2015).

GECES (Sub-group on Impact Measurement). (2013), "Proposed Approaches to Social Impact Measurement in European Commission legislation and in practice relating to: EuSEFs and the EaSI”, Brussels, European Commission. En línea: http://ec.europa.eu/internal_market/social_business/docs/expert-group/20131128impact-measurement-subgroup_en.pdf (Consulta: 11-05-2015).

Gershuny, J. (1983), Social Innovation and the Division of Labour. Oxford: Oxford University Press.

Godin, B. (2012), "Social Innovation: Utopias of Innovation from c. 1830 to the Present", Paper No. 11. Project on the Intellectual History of Innovation. Montréal: INRS.

Grupo Q-EPEA (2009), Barreras y oportunidades de innovación en el sector público vasco. Guipúzcoa: Fundación Q-EPEA.

Halvorsen, T. Hauknes, J. Miles, I. y Roste, R. (2005), "Innovation in the Public Sector. On the differences between public and private sector innovation”, Public Report No. D9. NIFU STEP, Oslo. En línea: http:// unpan1.un.org/intradoc/groups/public/documents/apcity/unpan046809.pdf. (Consulta 10-05-2015).

Harayama, Y. y Nitta, Y. (2011), “Introduction: transforming innovation to address social challenges”, en OECD, Fostering Innovation to Address Social Challenges.

Paris: OECD Publishing. En línea: http://www.oecd.org/science/inno/47861327.pdf (Consulta 11-05-2015).

Hartley J. (2005), “Innovation in Governance and Public Services: Past and Present", Public money \& Management, 25(1):27-34.

Heiskala, R. (2007), "Social innovations: structural and power perspectives", en T. Hämäläinen, y R. Heiskala, R, eds; Social innovations, institutional change and economic performance. Making sense of structural adjustment processes in industrial sectors, regions and societies, Finland: SITRA. DOI: 10.4337/9781847206992.00009.

Hillier, J, Moulaert, F. y Nussbaumer, J. (2004), "Trois essais sur le rôle de l'innovation sociale dans le développement territorial”. Géographie, Économie, Société, 2(6), pp. 129-152. DOI: 10.3166/ges.6.129-152.

Hochgerner, J. (2011), "The Analysis of Social Innovations as Social Practice”. En línea: http://www. socialinnovation2011.eu/wp-content/uploads/2011/04/The-Analysis-of-Social-Innovations-as-Social-Practice. pdf (Consulta 10-05-2015).

Howaldt, J. y Schwarz, M. (2010), Social Innovation: Concepts, research fields and international trends. En línea: http://www.asprea.org/imagenes/IMO\%20Trendstudie_Howaldt_englisch_Final\%20ds.pdf (Consulta: 15-05 -2015).

Hubert, A. (2010), Empowering people, driving change: Social innovation in the European Union. En línea: http:// www.net4society.eu/_media/Social_innovation_europe.pdf (Consulta: 15-05-2015).

Kesselring, A. y Leitner, M. (2008), Soziāle Innovationen in Unternehmen. Study, compiled by order of the Unruhe Stiftung. Vienna: ZSI.

Leadbeater, C. (1997), The rise of the social entrepreneur. London: NESTA.

Levesque, B. (2012), Social Innovation and Governance in Public Management Systems: Limits of NPM and search for alternatives?, Quebec: Centre de Recherche sur les Innovations Sociales (CRISES).

MaRS (2011), DRAFT Ontario's Social Innovation Policy Paper. En línea: http://www.marsdd.com/wp-content/ uploads/2012/10/Wiki-Social-Innovation-Policy-Paper-.pdf (Consulta: 10-05-2015).

Mguni, N. and Bacon, N. (2010), Taking the temperature of local communities. The Wellbeing and Resilence Measure (WARM), London: The Young Foundation. En línea: http://youngfoundation.org/publications/takingthe-temperature-of-local-communities-the-wellbeing-and-resilience-measure-warm/ (Consulta: 15-05-2015). 
Moulaert, F y Nussbaumer, J. (2005), “Defining social economy and its governance at the neighbourhood level: A methodological reflection”, Urban Studies, 42(11), pp. 2071-2088.

Moulaert, F; MacCallum, D; Mehmood, A, y Hamdouch; A. (2010), Social Innovation: Collective action, social learning and transdisciplinary research. Katarsis, EU‘s Framework Program 6. Final Report. En línea: http:// cordis.europa.eu/documents/documentlibrary/124376771EN6.pdf (Consulta: 14-05-2015)

Mulgan, G., Tucker, S., Ali, R., y Sanders, B. (2007). Social innovation: what it is, why it matters and how it can be accelerated. London: The Young Foundation. En línea: http://www.sbs.ox.ac.uk/faculty-research/skoll/ research/social-innovation-reports-resources/social-innovation-what-it-why-it-matters-how-it-can-beaccelerated (Consulta: 15-05-2015).

Murray, R, Caulier, J, y Mulgan, G. (2010): The open book of social innovation. London: The Young Foundation.

NAO. National Audit Office (2009): Innovation across central government. Report by the comptroller and auditor general | HC 12 Session 2008-2009 | 26 March 2009. London. En línea: http://www.nao.org.uk/wp-content/ uploads/2009/03/080912es.pdf (Consulta 10-05-2015).

Nauta, F, y Kasbergen, P. (2009), OECD Literature Review Public Sector Innovation. En línea: http://han. surfsharekit.nl:8080/get/smpid:15206/DS1 (Consulta: 11-05-2015).

Ngumi, N. y Bacon, N. (2010 Taking the temperature of local communities The Wellbeing and Resilience Measure (WARM). London: The Young Foundation. En línea: http://youngfoundation.org/wp-content/uploads/2012/10/ Taking-the-Temperature-of-Local-Communities.pdf (Consulta: 14-05-2015).

Ogburn, W. F. (1957), "Cultural Lag as Theory”. Sociology and Social Research, January-February: $167-174$.

Schumpeter, J. A. (1934), The Theory of Economic Development. Cambridge, MA: Harvard University Press.

Pol, E. y Ville, S. (2009): "Social innovation: Buzz word or enduring term?", Journal of Socio-Economics, 38 (6): 878-885. DOI: 10.1016/j.socec.2009.02.011.

Schmitz, B. Krlev, G. Mildenberger. G, Bund, E, y Hubrich, D. (2013), Paving the Way to Measurement-A Blueprint for Social Innovation Metrics. A short guide to the research for policy makers. (TEPSIE), European Commission, 7th Framework Programme, Brussels: European Commission. En línea: http://www.tepsie.eu/ images/documents/tepsie25.pdf (Consulta; 11-05-2015).

Thenint, H. (2010), “Mini Study 10 Innovation in the public sector”, Global Review of Innovation Intelligence and Policy Studies. Inno Grips: 1-51.

SIX y Young Fundation (2010), Study on social innovation. En línea: http://youngfoundation.org/wp-content/ uploads/2012/10/Study-on-Social-Innovation-for-the-Bureau-of-European-Policy-Advisors-March-2010.pdf. (Consulta: 15-05-2015).

Westley, F. y Antadze, N. (2010), “Making a Difference Strategies for Scaling Social Innovation for Greater Impact”, The Innovation Journal: The Public Sector Innovation Journal, Vol. 15(2): 1-19. En línea: http://www. innovation.cc/scholarly-style/westleyzantadze2make_difference_final.pdf. (Consulta: 10-05-2015).

Z.S.I. (2008), Simulating social development. En línea: https://www.zsi.at/object/publication/1399/attach/ZSI_ Profile_EN.pdf (Consulta: 10-05-2015). 